INPLASY

PROTOCOL

To cite: Sun et al. Effects of mental fatigue on decisionmaking skill among soccer players: A systematic review with a meta-analysis. Inplasy protocol 202190037. doi: 10.37766/inplasy2021.9.0037

Received: 13 September 2021

Published: 13 September 2021

Corresponding author:

Sun He

verson.upm@gmail.com

Author Affiliation:

Zhengzhou University

Support: None.

Review Stage at time of this submission: The review has not yet started.

Conflicts of interest: None declared.

\section{Effects of mental fatigue on decision-making skill among soccer players: A systematic review with a meta-analysis}

Sun, $\mathrm{H}^{1}$; Soh, $\mathrm{KG}^{2}$.

Review question / Objective: Does mental fatigue influence decision-making skill among soccer players?

Condition being studied: It has been well investigated that mental fatigue negatively influence physical performance among sports players, however, as the most essential skill (decision-making skill) has not been well examined in a systematic review and meta-analysis.

Information sources: EBSCOhost, Pubmed, Web of Science, Scopus, Google Scholar.

INPLASY registration number: This protocol was registered with the International Platform of Registered Systematic Review and Meta-Analysis Protocols (INPLASY) on 13 September 2021 and was last updated on 13 September 2021 (registration number INPLASY202190037).

\section{INTRODUCTION}

Review question / Objective: Does mental fatigue influence decision-making skill among soccer players?

Condition being studied: It has been well investigated that mental fatigue negatively influence physical performance among sports players, however, as the most essential skill (decision-making skill) has not been well examined in a systematic review and meta-analysis

\section{METHODS}

Participant or population: Soccer players. 
Intervention: Cognitive tasks used to induce mental fatigue.

Comparator: Mental fatigue vs. low/non mental fatigue.

Study designs to be included: RCT.

Eligibility criteria: English language; prior cognitive task induces mental fatigue; soccer players; decision-making skill was outcome.

Information sources: EBSCOhost, Pubmed, Web of Science, Scopus, Google Scholar.

Main outcome(s): Effects of mental fatigue on soccer decision-making skill.

Quality assessment / Risk of bias analysis: PEDro scale (www.pedro.org.au).

Strategy of data synthesis: All data about mental fatigue influences decision-making skills among soccer players will be together, whatever in small-side games, full-game or lab.

Subgroup analysis: Male and female.

Sensitivity analysis: To adjust for publication bias, a sensitivity analysis was conducted using the trim and fill method, with LO as the default estimator for the number of missing studies.

Country(ies) involved: China.

Keywords: mental fatigue; decisionmaking; soccer performance; soccer players.

Contributions of each author:

Author 1 - Sun He.

Author 2 - Soh Kim Geok. 